\title{
Reliability Issues Caused By The Retirement Of Large Thermal Generation Facilities: An Irish Case Study
}

Kyle Lawson

Technological University Dublin

Jane Courtney

Technological University Dublin, jane.courtney@tudublin.ie

Follow this and additional works at: https://arrow.tudublin.ie/engscheleart

Part of the Environmental Engineering Commons, and the Power and Energy Commons

\section{Recommended Citation}

K. Lawson and J. Courtney, "Reliability Issues Caused By The Retirement Of Large Thermal Generation Facilities: An Irish Case Study," 2019 54th International Universities Power Engineering Conference (UPEC), 2019, pp. 1-6, doi: 10.1109/UPEC.2019.8893641.

This Conference Paper is brought to you for free and open access by the School of Electrical and Electronic Engineering at ARROW@TU Dublin. It has been accepted for inclusion in Conference papers by an authorized administrator of ARROW@TU Dublin. For more information, please contact arrow.admin@tudublin.ie, aisling.coyne@tudublin.ie, gerard.connolly@tudublin.ie.

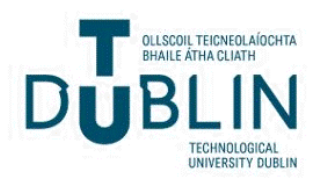




\title{
Reliability Issues Caused By The Retirement Of Large Thermal Generation Facilities: An Irish Case Study
}

\author{
Kyle Lawson ${ }^{1}$, Jane Courtney ${ }^{1}$, School of Electrical and Electronic Engineering Technological University Dublin, City Campus \\ Dublin, Ireland ${ }^{1}$. Corresponding author email: Kyle.Lawson@student.dit.ie
}

\begin{abstract}
Like all developed countries Ireland faces increasing pressure to reduce their carbon footprint. Part of the governments plans include the scaling back of fossil fuel generation facilities and increasing renewable resources. Moneypoint is Irelands only coal fired generation station. In 2025 Moneypoint is due to reach the end of its life cycle. At this point the Irish government will have to make a decission on the future of the generation facility. Currently Moneypoint is responsible for the generation of approximately 10 $\%$ of Irelands energy needs.
\end{abstract}

In this paper, the removal of Moneypoint from the Irish generation portfolio will be investigated. A series of simulations have been completed using historic demand and generation data. An initial assessment of the system was completed to verify the assessment technique. All three Moneypoint generation units were then removed and the relibaility of the system dropped dramatically. From this point assessments were completed to determine the quantity of wind generation that would be needed to bring the system back to a stable level. The assessments completed indicate that in 2025 an additional $3000 \mathrm{MW}$ of wind generation will be needed if Moneypoint is removed from the generation portfolio of the country.

\section{INTRODUCTION}

Since joining the European Union (EU) Ireland has been under increasing pressure to reduce it's emissions. In 2015 Ireland released a white paper identifying its plans to reduce carbon emissions. These plans included the phasing out of coal and peat burning generation stations [1].

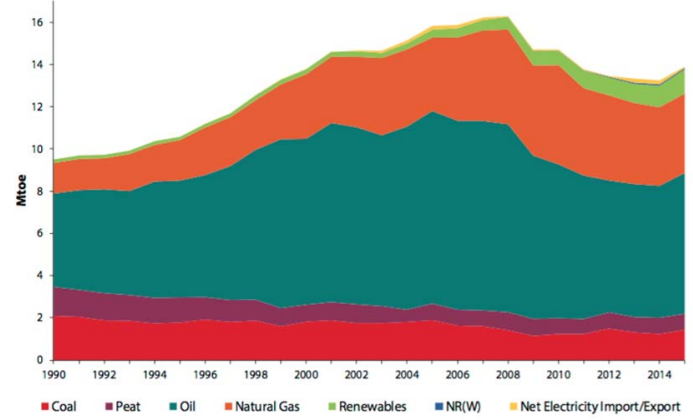

Figure 1 - Irelands Generation Breakdown

Figure 1 above shows how Irelands energy has been generated over the last 10 years [2]. Although there is an increasing amount of renewable energy generation being produced, the increased energy demands of a country with a growing economy currently cannot be met without an increase in fossil fuel generation.

With the immanent decommissioning of fossil fuel generation stations [1], there is set to be a generation shortfall within the country. An example of this is Moneypoint in Co. Clare, a coal fired generation station, set to be decommissioned in 2025. This generation station accounts for $20 \%$ of electricity demand in the Republic of Ireland [3].

Although efforts have been made in the past number of years to reduce the emissions from Moneypoint, including the investment of over $€ 500$ million to reduce the plant emissions in 2016 [3], major decisions concerning the long term use of the coal fired plant are unavoidable.
The government released a white paper in 2015 that targeted a reduced use of carbon heavy electricity generation plants, such as coal and peat, and also addressed the shift towards active customers [1]. Moneypoint reaches the end of its life cycle in 2025, at which point decisions regarding its future will be determined. The loss of Moneypoint from the grid will result in a loss of $915 \mathrm{MW}$ of generation power from the grid [3].

With ever increasing pressure being put on society to find renewable energy or environmentally friendly alternatives to fossil fuel generation, and an ever increasing requirement for energy in the future, it is more important than ever to plan how our country will meet its energy needs and its European targets [4]. The fines imposed by the European Union upon failure of meeting outlined emissions targets can have large economic consequences. If Ireland fail to meet their agreed upon emissions targets as part of the Kyoto Protocol it will result in a possible financial cost to the state of approximately $€ 90$ million [5].

Ireland has agreed to decrease it's ratio of fossil fuel to renewable generation significantly in the coming years. In 2014 approximately $8 \%$ of Irelands generation capacity came from renewable sources [2], the Kyoto target is to increase this percentage to $27 \%$ [5]. This piece of research will assess the reliability issues resulting from the closure of such a large generation station and investigate the possible generation replacements needed to ensure that the reliability of the grid does not suffer as a result of the closure of Moneypoint.

\section{RELATED WORK}

A. System Well-Being Assessment

A well-being assessment is aimed at assessing the distribution system during different modes of operation. Atwa et al. [6] provides a detailed outline of the various methods of system well-being assessments. In [7] a probabilistic approach of dealing with the uncertainty of wind generation was used. In [8] an analytical approache to model renewable generation 
considering correlation between the load and the renewable generation is developed. In [9] an approach based on the estimation of power loss supply probability of stand alne solar genration is developed. [10] develop and refine a method for the completion of well-being assessments based on a sequential approach to tabulate a loss of load expectancy with and without battery storage.

All of these well-being assessments require in depth data regarding the current system, this is highly sensitive data that is not readily available and therefor thi smethod of assessment would not be feasable.

\section{B. IEEE-RTS}

The IEEE Reliability Test System (RTS) is a defined system with defined parameters for generation, load and transmission system characteristics. It was developed to conduct and develop reliability assessments, originally limited to small studies on bulk supply power systems. It is constantly being improved and is now capable of reliability assessments on a 24 bus system, as shown in [11].

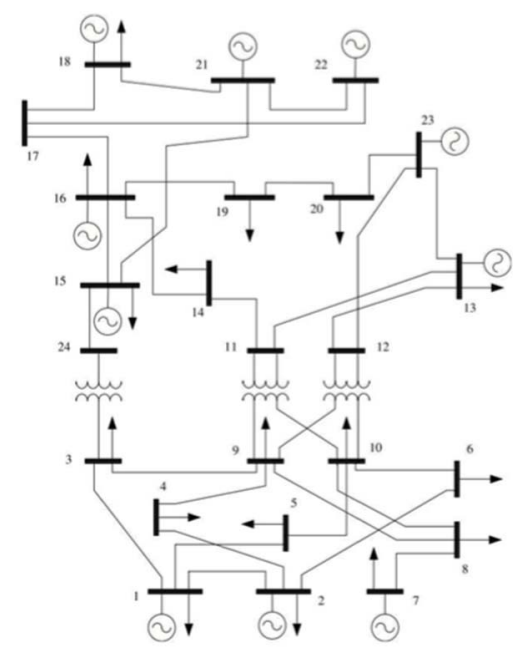

Figure 2 - IEEE RTS 96 - 24 Bus System

This test system is an ideal method for the assessment of any reliability assessment developed, but it is not suitble for manipulation into a method of assessment to determine the effects of removing Moneypoint from the Irish generation portfolio. The system would have to be heavily modified in order to make it accurately represent the Irish system. Even after heavy modification it would only represent a small section of the Irish system and therefore would not be an accurate method of assessment.

\section{Markov Models}

A Markov Model is a simplified method of assessing a systems failure rate and quantifying system reliability [12]. A Markov Model can be applied to all engineering applications by following international guidelines which outline the application of Markov techniques for dependability analysis. The Markov Model outlined in Figure 3 depicts the complexity of the assessment on a two-generator system, where there are four possible states. In the case of a generation system it shows the probability of various generation units being available or unavailable based on the probability of them moving from the generation to nongeneration state [13].

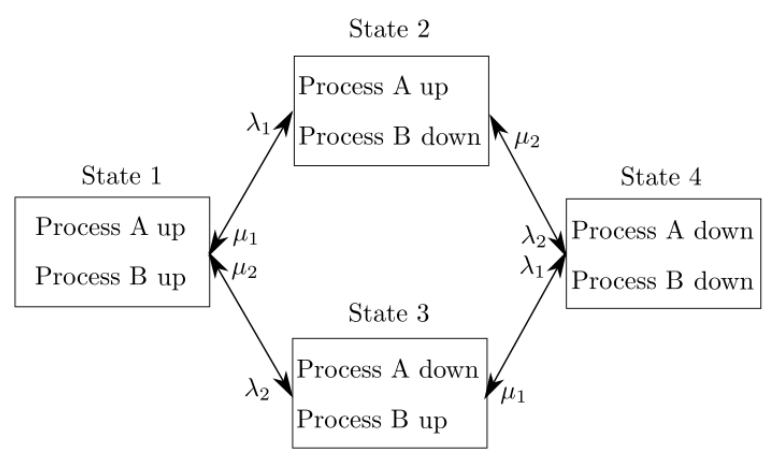

Figure 3 - Markov Model State Example [14]

The issue with this method of assessment is the information on generation units that is required, and also the complexity of a calculation for a whole generation system comprising of over a hundred generation units such as the Irish system. Markov models define the number of states as:

$$
S=2^{G}
$$

where: $\mathrm{S}=$ the number of possible states.

$\mathrm{G}=$ the number of generation units.

\section{Reliability Indices}

All reliability methods commonly share reliability indices to assess the systems effectiveness. There are two indices in particular that are recognised as the industry standard.

\section{1) Loss of load probability (LOLP)}

This is a measure of the probability of a generation system being unable to supply the loads of the system [15].

$$
L O L P_{t}=\sum_{i=1}^{n} p\left(X_{i}<L_{t}\right)
$$

where: $\mathrm{n}$ is the number of generation system capacity states. $\mathrm{Xi}$ is the capacity level of the generation system state $\mathrm{i}$.

$\mathrm{Lt}$ is the half hourly peak load on the system.

\section{2) Loss of load expectancy ( $\mathrm{LOLE})$}

LOLE is the expected hours per year that the generation system will not be able to supply the load demands of the system, resulting in loss of power to load points [15].

$$
L O L E=\frac{1}{2} \sum_{t=1}^{T} L O L P_{t}
$$

where: $\mathrm{T}$ is the time horizon.

The methodology detailed below uses readily available data to determine the LOLP and LOLE for a given year.

\section{A. System Demand Modelling}

The load model that will be used in this assessment is developed by tabulating the hourly peak loads over a oneyear period. The load data has been obtained from Eirgrids online database [16].

The probability table developed gives the probability of a certain MW capacity outage occuring. In order to determine what capacity outage will result in a loss of load for each 
hour the following must be calculated for each hour of the chosen period:

$$
\mathrm{O}=\mathrm{G}_{\mathrm{MAX}}-\mathrm{D}
$$

where: $\mathrm{O}$ is the MW outage that will be compaired to the Capacity Outage Probability Table (COPT) to determine the probability of the generation system not being capable of supplying the load.

$\mathrm{G}_{\text {MAX }}$ is the maximum generation capacity based on the Eirgrid data obtained for the generation units on the system.

$\mathrm{D}$ is the demand.

\section{B. System Generation Modelling}

The capacity model utilized is based on the recursive algorithm first presented by Billinton and Allan [15]. The algorithm is used to calculate the Loss of Load Expectancy (LOLE) by determining the amount of hours in the year when the generation system is not capable of supplying the system load.

The capacity outage table (COPT) is developed using forced outage rate (FOR) and capacity data of every generation unit connected to the grid. The data obtained to complete this assessment is taken from the September 2018 Eirgrid capacity report.

It is also important to note the reasoning behind choosing September 2018 data and not something more recent. This decision was made due to extensive work that began in early 2019 in Moneypoint, this work resulted in one of the generation units being taken out of service. The loss of this large generation unit is not something that the system has to deal with during a typical year. As a result the decision was made to take data from the period before this generation unit outage [17].

Wind generation details for the same period were obtained from the Eirgrid database [16]. This data was manipulated in order to determine the FOR and generation capacity factor (a factor used to de-rate wind resources capacity to compensate for the unpredictable and undependable nature of the resource). For example, installing $50 \mathrm{MW}$ of wind turbines does not mean that there is always $50 \mathrm{MW}$ available. There is the possibility that there may be if the correct wind blows, however there is an equally great chance that the maximum generation capacity will not be attainable. Typical values for this are in the region of $20-30 \%$ [18].

Rather that just apply a standard factor to the wind generation facilities in Ireland the \% capacity was calculated as follows:

$$
\% \text { Capacity }=\frac{\text { Wind Availability }}{\text { Wind Capacity }} \times 100
$$

Based on the wind availability and generation figures outlined from 2014 to 2018 it is also possible to determine the percentage availability from historic values rather than applying an industry standard figure, this calculation was completed as follows:

$$
\% \text { Availability }=\frac{\text { Wind Generation }}{\text { Wind Availability }} \times 100
$$

The percentage availability and capacity were calculated for a five-year period based on historical values and the average was taken and applied to the generation data (Average \% Capacity $=28.3 \%$, Average $\%$ Availability $=93.9 \%$ ).

\section{COPT Development}

A capacity table is simply a probabilistic description of the possible capacity states of the system being evaluated [19]. In order to do so the probability of each possible capacity output scenario must be tabulated.

To develop the COPT the probabilities of the various generation units must be convolved together to find the probability of a certain generation capacity being available at any time.

For the purpose of this assessment all generation units will be treated as either up (generating at full capacity) or down (not generating at all). This simplifies the tabulation of the COPT; it is now only necessary to know the probability that the unit is available for generation and the probability that the unit is unavailable, which is linked to the forced outage rate of the unit.

With the system simplified by limiting generator states to two, there are $2 \mathrm{n}$ possible different capacity states for each generator unit:

$$
P(X=x i)=\left\{\begin{array}{cc}
1-q & x i=C i \\
q & x i=0
\end{array}\right.
$$

where: $\mathrm{Ci}$ is the nominal capacity.

$\mathrm{X}$ (and $\mathrm{xi}$ ) is the outage capacity.

$\mathrm{Q}$ is the state definition.

This can be expanded to develop the state cumulative probability distribution function by summing up individual state probabilities for all capacities less than xi:

$$
P(X=x i)=\left\{\begin{array}{cc}
0 & x i<0 \\
q & 0 \leq x i \leq C i \\
1 & x i \geq C i
\end{array}\right.
$$

For each capacity outage there is an associated forced outage rate, individual state probability and cumulative state probability, based on the summation of the generation units used to produce that capacity output. The individual state probability is not of interest for this assessment but the cumulative probability is the value which will be used to determine the LOLP value for the time period of the assessment [19]:

$$
P(j)=\frac{N !}{j ! N-j}-X A^{N-j} X U^{j}
$$

where: $\mathrm{U}$ is unit unavailability.

A is unit availability.

$\mathrm{N}$ is the number of units.

$\mathrm{J}$ is the outage state.

$P(j)$ is the probability of outage state $j$.

The COPT is then used to determine the probability of loss of load for each hour of the year, based on the peak demand data from the database.

The hourly probabilities are then tabulated to give a yearly probability for the loss of load, LOLP:

$$
P=1-\left[\left(1-P_{1}\right) \times\left(1-P_{2}\right) \times\left(1-P_{3}\right) \ldots \ldots\left(1-P_{n}\right)\right]
$$

where: $\mathrm{P} 1$ is the probability of the generation not being capable of supplying the load for hour 1 . 
P2 is the probability of the generation not being capable of supplying the load for hour 2

$\mathrm{Pn}$ is the probability of the generation not being capable of supplying the load for the final hour of the time period chosen.

The result of the probability calculation is the loss of load probability (LOLP). To convert from LOLP to loss of load expectancy (LOLE) the following simple calculation is completed:

$$
L O L E=L O L P \times 8760
$$

This equation converts from loss of load probability (a value from $0-1$ ) to loss of load expectancy, a value of hours per year.

\section{RESULTS}

\section{A. 2017-2018 Reliability Assessment}

The data discussed in the methodology section, found on the Eirgrid online database [16], was used to complete the reliability assessment following the outlined methodology.

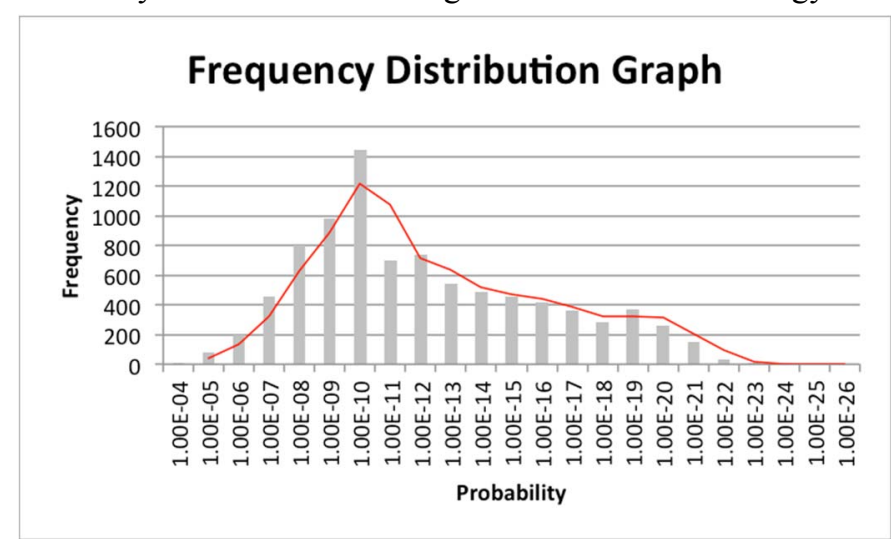

Figure 4 - Frequency Distribution 2017 - 2018

The frequency distribution graph shows that the probability of having a capacity outage. It can be seen from this graph that there is a very slim chance of there being a capacity outage; even at the highest probability the values are less than 0.000001 . This very low probability is reflected when the reliability indices are examined.

\begin{tabular}{|c|c|}
\hline \multicolumn{2}{|c|}{$\mathbf{2 0 1 7} \mathbf{- 2 0 1 8}$ Reliability Assessment } \\
\hline \hline $\begin{array}{c}\text { Loss of load probability } \\
\text { (LOLP) }\end{array}$ & 0.0033 \\
\hline $\begin{array}{c}\text { Loss of load expectancy } \\
\text { (LOLE) }\end{array}$ & 2.85 hrs per year \\
\hline \multicolumn{2}{|c|}{ Table 1 - Reliability Indices 2017-2018 } \\
\hline
\end{tabular}

\section{B. 2015 - 2016 Reliability Assessment}

The following assessment was completed as a verification of the functionality of the code.

\begin{tabular}{|c|c|}
\hline \multicolumn{2}{|c|}{$\mathbf{2 0 1 5}$ - 2016 Reliability Assessment } \\
\hline \hline $\begin{array}{c}\text { Loss of load probability } \\
\text { (LOLP) }\end{array}$ & 0.0064 \\
\hline $\begin{array}{c}\text { Loss of load expectancy } \\
\text { (LOLE) }\end{array}$ & 5.61 hrs per year \\
\hline
\end{tabular}

Table 2 - 2015 - 2016 Reliability Indices

The peak of the probability distribution graph has shifted slightly (when compared to the $2017-2018$ results) with the most frequent probability being higher; this suggests that the system was slightly less reliable. This is feasible as there has been a significant increase in wind energy development in the past few years. This is highly efficient and reliable energy, and due to the priority dispatch of wind it is almost always dispatched unless there is curtailment due to the penetration values of wind at any time.

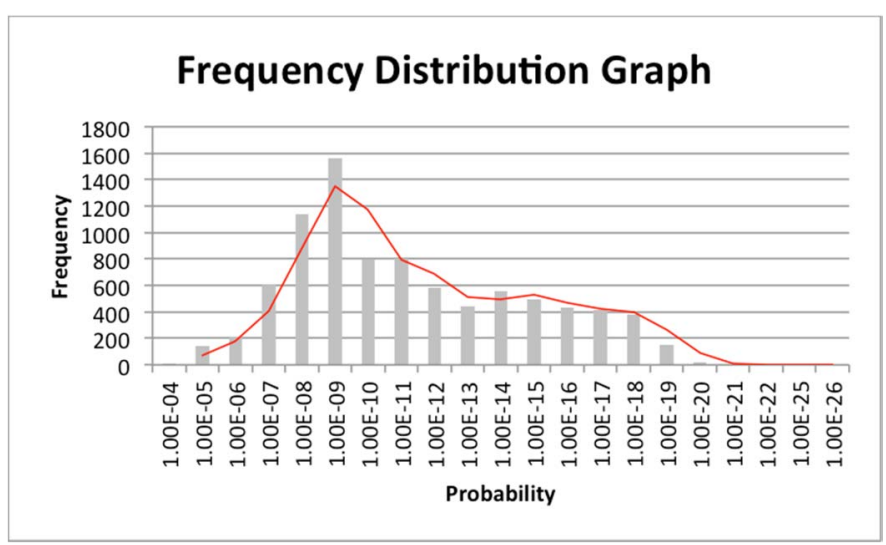

Figure 5 - Frequency Distribution 2015 - 2016

The reliability indices shown in Figure 2 verify the analysis of the frequency distribution graph for the time period. The LOLE value for this period is slightly higher than that from the $2017-2018$ period assessment. The system is still shown to be very stable and comes in comfortably below the national target of 8 hours per year.

This assessment proves that the results obtained from the 2017 - 2018 and 2015 - 2016 period are different due to a different demand and generation system composition. This test run proves that the code developed to complete the reliability assessment functions as expected and is capable of showing differences in reliability for two separate time periods.

\section{Removal of Moneypoint}

The three $285 \mathrm{MW}$ generation units of Moneypoint were then removed one unit at a time and the LOLP and LOLE values after each simulation were recorded. The results are depicted in Table 3. The reliability indices shown prove that the removal of a large generation source, such as Moneypoint has a dangerous effect on system stability and reliability.

\begin{tabular}{|c|c|c|c|}
\hline \multicolumn{4}{|c|}{$\begin{array}{c}\text { Reliability Assessment Results } \\
\text { (Moneypoint removal) }\end{array}$} \\
\hline \hline $\begin{array}{c}\text { Units } \\
\text { Removed }\end{array}$ & $\begin{array}{c}\text { Capacity } \\
\text { Removed }\end{array}$ & LOLP & $\begin{array}{c}\text { LOLE } \\
\text { (hrs per year) }\end{array}$ \\
\hline No Units & $0 \mathrm{MW}$ & 0.0033 & 2.9 \\
\hline One & $285 \mathrm{MW}$ & 0.012 & 10.8 \\
\hline Two & $570 \mathrm{MW}$ & 0.0078 & 68.3 \\
\hline Three & $855 \mathrm{MW}$ & 0.0141 & 123.4 \\
\hline
\end{tabular}

Table 3 - Reliability Indices (following the removal of Moneypoint)

\section{Replacement of Moneypoint}

The reliability issues as a result of the removal of Moneypoint have been now been proven, the question that arises from these results is what level of generation will be 
needed to bring the system back to reasonable reliability levels with Moneypoint removed.

The COPT method of assessment used makes this task quite difficult. Due to the nature of how the COPT is created the addition of new generation units will result in a change of LOLP and LOLE values. This is a short fall of this method of assessment.

The focus of this investigation will be the replacement of Moneypoint with wind energy, in order to do so two methods will be used. For all of these simulations Moneypoints generation capacity has been removed from the generation portfolio.

\section{1) Generation Unit Substitution}

In order to remove Moneypoint units from the previous sections, assessment the availability of the units was set to 0 . It is possible to now substitute these units with wind energy. Using the availability percentage calculated previously $(93.85 \%)$. By adding one wind generation unit of $285 \mathrm{MW}$ capacity it implies that there is a wind farm with the installed capacity of $1000 \mathrm{MW}$. This is due to the wind capacity factor discussed previously.

\begin{tabular}{|c|c|c|c|}
\hline \multicolumn{4}{|c|}{$\begin{array}{c}\text { Reliability Assessment Results } \\
\text { (Moneypoint substituted with wind energy) }\end{array}$} \\
\hline \hline $\begin{array}{c}\text { Units } \\
\text { Substituted }\end{array}$ & $\begin{array}{c}\text { Capacity } \\
\text { Removed }\end{array}$ & LOLP & $\begin{array}{c}\text { LOLE } \\
\text { (hrs per year) }\end{array}$ \\
\hline One Unit & $285 \mathrm{MW}$ & 0.0022 & 19.7 \\
\hline Two Units & $570 \mathrm{MW}$ & 0.0003 & 2.9 \\
\hline
\end{tabular}

Table 4 - Reliability Assessment of Moneypoint Substituted with wind energy The reliability indices shown indicate that the addition of 1000 MW of wind energy is not sufficient to replace Moneypoint and result in a system which complies with the standards outlined by the government. The addition of 2000 MW of wind generation appears to be sufficient to replace the Moneypoint generation facility and maintain grid reliability.

\section{2) Load Manipulation}

To determine the wind generation required to replace Moneypoint the demand data was manipulated to find the generation shortfall. Removing Moneypoint resulted in a decrease in system reliability, however, by decreasing the demand data it is possible to determine the generation required from wind to return the system to a stable state. This is achieved by scaling the demand data back in steps of $5 \%$ until the LOLE values are within the desired range. This scaling factor can then be used to determine the TWh and subsequently the TW/MW generation needed to overcome the generation shortfall resulting from the removal of Moneypoint.

The reliability indices in Table 5 show that a $10 \%$ demand reduction is necessary to ensure a reliable system with LOLE less than 8 hours per year. This means that the generation shortfall following the removal of Moneypoint is equal to $10 \%$ of the system demand.

This equates to $\sim 2.9 \times 10^{6} \mathrm{MWh}$, or $\sim 327.6 \mathrm{MW}$ of generation capacity. If this capacity is to be supplied by wind generation the magnitude of installed capacity must be increased due to the capacity factor of wind. Based on historical data this factor is $28.3 \%$. This would mean that the capacity of wind needed to maintain system reliability after Moneypoint is removed is $\sim 1150 \mathrm{MW}$ of installed capacity.

\section{7 - 2018 Reliability Assessment - Moneypoint Removed Demand Scaling}

\begin{tabular}{|c|c|c|}
\hline \hline $\begin{array}{c}\text { Demand } \\
\text { Reduction (\%) }\end{array}$ & LOLP & $\begin{array}{c}\text { LOLE } \\
\text { (hrs per year) }\end{array}$ \\
\hline 5 & 0.0022 & 20 \\
\hline 10 & 0.0031 & 2.8 \\
\hline
\end{tabular}

Table 5 - Reliability Indices with reduced demand

\section{E. Future Planning}

As Ireland is a rapidly developing country it is important to ensure that the level of generation available is suitable to meet ever growing demands of the country. It is anticipated that when the demand is increased this additional generation may not be enough to cope with the increased demand.

The Eirgrid capacity statement lists that the median demand for 2025 is estimated to be $33.7 \mathrm{TWh}$ [20]. The demand data used for the assessment will be scaled up to meet this demand range and the simulation will be completed again with this increased demand.

The total demand being used for this assessment summed to $28.7 \mathrm{TWh}$. This was then used with the predicted demand for 2025 to determine what percentage scaling would be needed to complete the simulation with the increased demand. The calculation used to determine the scaling required is shown below:

$$
\frac{\text { Increased Demand }}{\text { Demand }} \times 100=\frac{5}{28.7} \times 100=17 \%
$$

The demand data was scaled up by $17 \%$ and the simulation with $2000 \mathrm{MW}$ of wind generation was completed. The LOLE value from this simulation was much higher than the specified 8 hours per year. In order to assess the results of adding an extra $1000 \mathrm{MW}$ of wind capacity a subsequent simulation was completed.

Scaling up the demand data to simulate the increased demand predicted in 2025 resulted in a substantial increase in LOLE. In the previous section $2000 \mathrm{MW}$ of wind generation were added to ensure LOLE values for the system without Moneypoint were less than 8 hours per year. With the increased demand it was determined that more than 3000 MW of wind energy would be required to ensure system stability.

The reliability indices show that even with $3000 \mathrm{MW}$ of extra wind capacity installed there will be reliability issues resulting from the removal of Moneypoint.

\section{Conclusion}

The work completed as part of this research was successful in determining the reliability and adequacy effects resulting from the removal of Moneypoint generation station from the generation portfolio of the country. The $\mathrm{m}$-file developed was used with data obtained from the Eirgrid database to run a series of assessments used to determine the current system reliability and investigate a number of scenarios. Ireland has a target of achieving system reliability and adequacy that results in less than 8 hours of load loss per year. 
The first assessment showed that during the 2017-2018 period there was a LOLE of 2.85 hours per year. This value is far below the system target, this is to be expected from a country with what is perceived as a reliable electricity grid. To verify the functionality of the code a second year was used, the LOLE value obtained was 5.61 hours per year, thus validating the codes functionality. For all subsequent tests the 2017-2018 demand and generation data were used.

The focus of this work was to assess the effects of removing Moneypoints generation capacity from the grid. In order to do so the three $285 \mathrm{MW}$ generation units were removed one at a time and the reliability of the system was assessed for each scenario. The removal of one unit of Moneypoints generation was enough to result in a system that did not meet the targets of reliability. The removal of the two other units saw the LOLE value soar to over 100 hours per year, the equivalent of $1.5 \%$ of the year.

Three simulations were completed with wind as a substitute for Moneypoint's generation capacity. Firstly, Moneypoint was substituted with wind. Secondly, demand scaling was used to determine the shortfall that wind would need to make up to maintain system reliability. These methods were used to determine that approximately $1500 \mathrm{MW}$ of wind capacity would be needed to replace Moneypoint. Finally, a future assessment was completed based on the forecast increase in demand by 2025 . This assessment concluded that more than 3000 MW of wind capacity would be needed to ensure system stability.

The simulations completed show that the removal of Moneypoint will have a large effect on the system adequacy and reliability. It has also been proven that replacing Moneypoint with wind energy alone is not feasible. Adding 3000 MW of wind generation will not even be sufficient based on Eirgrids forecasted demand increases. This emphasizes the importance of a generation portfolio that is varied, and develops wind, solar, battery storage and thermal plants sufficiently to ensure grid stability. It was beyond the scope of this work to look further into the generation development planning, this is an area of research that could be used to complete long term economic planning for the country.

\section{REFERENCES}

[1] DCENR, "Ireland's Transition to a Low Carbon Energy Future 2015-2030," Gov. Pap., p. 122, 2015.

[2] Seai, “Energy in Ireland 1990 - 2015,” p. 86, 2014.

[3] ESB International, "Retrofit to Moneypoint Coal Fired Power Plant," 2016. [Online]. Available: https:/www.esbinternational.ie/our-solutions/casestudies/2016/09/05/fgd-scr-retrofit-to-moneypoint-3x-300-mw-coal-fired-power-plant. [Accessed: 02Dec-2017].

[4] D. Dineen, M. Howley, M. Holland, and E. Cotter, "Energy Security in Ireland: A Statistical Overview 2016," p. 80, 2016.

[5] DPER, "Future Expenditure Risks associated with Climate Change/Climate Finance," pp. 1-6, 2014.
Y. M. Atwa, E. F. El-Saadany, and A.-C. Guise,
"Supply Adequacy Assessment of Distribution System Including Wind-Based DG During Different Modes of Operation," vol. 25, no. 1, pp. 78-86, 2010.

[7] M. A. Khallat and S. Rahman, "A Probabilistic Approach to Photovoltaic Generator Performance Prediction," IEEE Trans. Energy Convers., vol. EC-1, no. 3, pp. 34-40, 1986.

C. Singh and A. Lago-Gonzalez, "Reliability Modeling of Generation Systems including Unconventional Energy Sources," IEEE Trans. Power Appar. Syst., vol. PAS-104, no. 5, pp. 10491056, 1985.

[9] L. L. J. Bucciarelli, "Estimating loss-of-power probabilities of stand-alone photovoltaic solar energy systems," Sol. Energy1, vol. 32, no. 2, pp. 205-209, 984.

[10] R. Billinton and Bagen, "A sequential simulation method for the generating capacity adequacy evaluation of small stand-alone wind energy conversion systems," IEEE CCECE2002 Can. Conf. Electr. Comput. Eng., 2002.

[11] C. Grigg et al., "The IEEE Reliability Test System 1996. A report prepared by the Reliability Test System Task Force of the Application of Probability Methods Subcommittee," IEEE Trans. Power Syst., vol. 14, no. 3, pp. 1010-1020, 1999.

[12] R. E. Brown, R. D. Christie, and R. Fletcher, "Using Hierarchical Markov Modeling,” vol. 11, no. 4, 1996.

[13] I. W. Soro, M. Nourelfath, and D. Ait-Kadi, "Performance evaluation of multi-state degraded systems with minimal repairs and imperfect preventive maintenance," Reliab. Eng. Syst. Saf., vol. 95, no. 2, pp. 65-69, 2010.

[14] Eval, "Multiple failure probability in Markov Process," 2018. [Online]. Available:

https://math.stackexchange.com/questions/2794215/ multiple-failure-probability-in-markov-process.

[15] R. N. Billinton, R. and Allan, Reliability Evaluation of Power Systems. Plenum Press, New York and London, 1984.

[16] Eirgrid, "Renewable Energy," 2019. [Online]. Available: http://www.eirgridgroup.com/how-thegrid-works/renewables/. [Accessed: 06-Apr-2019].

[17] EirGrid, "EirGrid Monthly Availability Report September 2018," 2018.

[18] A. S. Dobakhshari and M. Fotuhi-firuzabad, "A Reliability Model of Large Wind Farms for Power System Adequacy Studies," vol. 24, no. 3, pp. 792801, 2009.

[19] A. Kumar, S. Sehgal, D. Arora, and A. Soni, "CAPACITY OUTAGE PROBABILITY TABLE CALCULATION ( COPT ) OF HARYANA POWER," vol. 2, no. 2, 2013.

[20] EirGrid and SoNi, "All-Island Generation Capacity Statement 2012-2021," p. 7, 2012. 